\title{
Contribution of foods consumed away from home to energy intake in Brazilian urban areas: the 2008-9 Nationwide Dietary Survey
}

\author{
Ilana Nogueira Bezerra* ${ }^{1 *}$, Amanda de Moura Souza ${ }^{1}$, Rosangela Alves Pereira ${ }^{2}$ and Rosely Sichieri ${ }^{1}$ \\ ${ }^{1}$ Department of Epidemiology, Institute of Social Medicine, State University of Rio de Janeiro, Rua São Francisco Xavier, 524, \\ $7^{\circ}$ andar, Bloco E, Cep 20550-900, Rio de Janeiro, RJ, Brazil \\ ${ }^{2}$ Department of Nutrition, Federal University of Rio de Janeiro, Avenida Carlos Chagas Filho, 373, Edificio do Centro de \\ Ciências da Saúde, Bloco J, $2^{\circ}$ andar, Cidade Universitária, Cep 21941-590, Rio de Janeiro, RJ, Brazil
}

(Submitted 15 December 2011 - Final revision received 14 June 2012 - Accepted 14 June 2012 - First published online 31 July 2012)

\begin{abstract}
The objectives of the present study were to estimate the dietary contribution of away-from-home food consumption, to describe the contribution of away-from-home foods to energy intake, and to investigate the association between eating away from home and total energy intake in Brazilian urban areas. In the first Brazilian Nationwide Dietary Survey, conducted in 2008-9, food records were collected from 25753 individuals aged 10 years or older, living in urban areas of Brazil. Foods were grouped into thirty-three food groups, and the mean energy intake provided by away-from-home food consumption was estimated. Linear regression models were used to evaluate the association between away-from-home food consumption and total energy intake. All analyses considered the sample design effect. Of the total population, $43 \%$ consumed at least one food item away from home. The mean energy intake from foods consumed away from home was $1408 \mathrm{~kJ}(337 \mathrm{kcal})$, averaging $18 \%$ of total energy intake. Eating away from home was associated with increased total energy intake, except for men in the highest income level. The highest percentage of away-from-home energy sources was for food with a high content of energy, such as alcoholic beverages (59\%), baked and deep-fried snacks (54\%), pizza (42\%), soft drinks (40\%), sandwiches (40\%), and sweets and desserts (30\%). The consumption of foods away from home was related to a greater energy intake. The characterisation of away-from-home food habits is necessary in order to properly design strategies to promote healthy food consumption in the away-from-home environment.
\end{abstract}

Key words: Away-from-home foods: Energy intake: Dietary surveys

Several factors contribute to energy intake that exceeds daily requirements ${ }^{(1)}$. Available data suggest that foods from away-from-home sources are higher in energy than foods prepared at home ${ }^{(2-4)}$. Cross-sectional studies have shown positive associations between eating away from home and total energy intake. Many studies have indicated that consumers of away-from-home foods present higher energy and higherenergy-dense food intake than non-consumers ${ }^{(5)}$. In addition, eating away from home is associated with a higher consumption of sugar-sweetened beverages and a lower consumption of milk, fruits and vegetables ${ }^{(6,7)}$.

Longitudinal studies have suggested that frequent awayfrom-home food consumption is associated with higher energy intake and excessive weight gain. The data from a prospective Spanish dynamic cohort of 9182 university graduates who were followed for an average of 4.4 years indicated that those who ate away from home two or more times per week had a higher risk of gaining $2 \mathrm{~kg}$ or more per year than those who did not eat away from home ${ }^{(8)}$. Among a population of 891 healthy adult women, increases in fast-food meal intake per week over a 3-year period were associated with an increase in total energy intake of $234 \mathrm{~kJ} / \mathrm{d}(56 \mathrm{kcal} / \mathrm{d})^{(4)}$.

Studies on energy and nutrient intakes related to awayfrom-home eating have only been conducted in the past few years and mainly in developed countries, such as the USA, Australia and various European countries ${ }^{(9-14)}$. There have been some studies conducted in low- and middle-income countries $^{(15-17)}$, but little is known about the impact of away-from-home food consumption on the total energy intake of individuals from a country undergoing rapid socioeconomic development.

Since 1970, Brazil has experienced an increase in the prevalence of overweight and obesity. Trends in household food availability clearly indicate important changes that might be contributing to the increasing prevalence of overweight and obesity. The inclusion of sugar-sweetened beverages and processed food in household expenses is increasing along with the decrease in the household availability of traditional Brazilian foods, such as rice and beans ${ }^{(18)}$. Moreover, in the same period, expenditure on foods consumed away from 
home has increased while the energy obtained from the consumption of household food has decreased ${ }^{(19)}$. As budget data indicate that the inclusion of away-from-home foods in total household food expenditures has become more important, the energy content associated with such foods may play an important role in the dietary profile of the Brazilian population.

In Brazil, household food availability and expenditure data, including data on foods consumed away from home, have been used to estimate food consumption ${ }^{(18,19)}$. This is the first study to estimate energy intake from foods consumed away from home based on data from an individual dietary intake survey carried out in a representative sample of the Brazilian urban population aged 10 years or older. The objectives of the present study were to estimate the populationbased prevalence of away-from-home food consumption, to describe the contribution of away-from-home foods to energy intake, and to investigate the association between eating away from home and total energy intake.

\section{Methods}

The present study analysed the data obtained from the Brazilian Nationwide Dietary Survey, which was conducted along with the 2008-9 Household Budget Survey by the Brazilian Office of Geography and Statistics. A representative sample of Brazilian households was selected using a two-stage cluster sampling design. In the first stage, census tracts, the primary sampling units, were selected by systematic sampling with proportional probability to the number of households. In the second stage, households were selected by simple random sampling. The primary sampling units were stratified to include representives of all Brazilian regions, urban and rural areas, and different socio-economic levels. The 2008-9 Household Budget Survey sample included 55970 households from 4696 census tracts. The Brazilian Nationwide Dietary Survey investigated 13569 households, randomly selected from the 2008-9 Household Budget Survey sample, assuring that all sectors selected for the Household Budget Survey 2008-9 were represented in the dietary survey sample. Individuals aged 10 years or older ( $n$ 34003) living in the selected households were included in the dietary survey. Most of the away-from-home eating occurs in urban areas, since in rural areas, only $9 \%$ of total energy intake came from away-fromhome eating. Therefore, for the purpose of the present paper, we included only individuals living in the urban areas of Brazil, yielding a final sample of 25753 individuals.

\section{Assessment of dietary intake}

Dietary intake data were obtained by trained interviewers during the household survey. Individuals aged 10 years or older were requested to keep records of all foods and beverages consumed on two non-consecutive days. All respondents received a booklet with explanations on how to fill out the records and with pictures of tableware to help them estimate the amount of food consumed. Interviewers reviewed the records and entered the data in a computer database at the household. In addition, interviewers probed respondents with questions over usually forgotten items, such as small snacks, sweets and beverages, and verified that all $3 \mathrm{~h}$ periods without food intake and records with less than five items were corrected, following the multiple-pass method to accurately record all possible foods consumed ${ }^{(20)}$. This allowed the filling-in of incomplete data by interviewing family members. Reported food amounts were transformed to grams or millilitres, and energy intake was estimated using a food composition table and a food portion table specially developed for the survey ${ }^{(21,22)}$. Standard recipes were created and nutritional information was based on the Brazilian Table of Food Composition and the Nutrient Data System for Research.

The definition of away-from-home foods consumed includes all foods and drinks, except water, that were purchased and consumed away from home. This definition has been used in other studies ${ }^{(19,23)}$ and does not include foods that were prepared at home and consumed away from home and ready-to-eat foods that were purchased away from home, but consumed at home. For this analysis, we evaluated the 1st day dietary record, which is typically better recorded than the following days ${ }^{(24)}$.

\section{Other variables}

Sociodemographic characteristics were collected during the household interviews. Monthly per capita income was calculated from all household monetary and non-monetary incomes, including gifts, donations, employment, self-employment and participation in cash transfer programmes. The total household income was divided by the number of members in the household to calculate the per capita household income and was evaluated in quartiles: up to US\$127; between US\$127 and 236; between US\$236 and 499; more than 499 dollars per capita per month.

\section{Analyses}

Analyses were stratified by age groups of adolescents (10-19 years old), adults (20-59 years old) and elderly (60 years old or more). All foods reported in the survey were grouped into thirty-three food groups, according to their nutritional content and to the way they are commonly consumed. We also grouped foods together that are usually consumed away from home. The energy intake from each food group was calculated and the mean amount corresponding to awayfrom-home eating was estimated. The percentage of energy consumed away from home was estimated according to sex, age groups and income levels.

Linear regression models were used to evaluate the association between away-from-home eating (independent variable) and energy intake (dependent variable). The consumption of food away from home was evaluated as a dichotomous variable (yes/no), identifying whether individuals consumed at least one item away from home. Energy intake was log-transformed to better approximate a normal distribution. The models were adjusted for age and income. Both age and income were treated as continuous variables, and the

\footnotetext{
the records and entered the data in a computer database at
} 
interactions between away-from-home eating and income were tested.

Linear trends for away-from-home energy intake across the income levels were tested using linear regression models with away-from-home energy intake as the dependent variable and income as the independent continuous variable.

All statistical analyses were weighted and performed using survey procedures from SAS release 9.1.3 (2003, SAS Institute) to take into account the sample design effect. Subpopulation analyses were carried out with the domain statement, and smsub and sregsub SAS macros were used to properly incorporate the domain statement into the ratio and linear regression analyses, respectively. Weight factors were corrected for non-response, thus allowing populationrepresentative estimates.

\section{Results}

The mean age of the population was 36.7 ( $\mathrm{SE} 0.2$ ) years. Of the study population, $21 \%$ were adolescents (10-19 years old), $66 \%$ were adults (20-59 years old) and 13\% were elderly (60 years old or above). The mean per capita household income was US\$378 (SE 9.5). Women comprised $52.5 \%$ of the population. The prevalence of overweight (BMI $\geq 25 \mathrm{~kg} / \mathrm{m}^{2}$ and $<30 \mathrm{~kg} / \mathrm{m}^{2}$ ) and obesity (BMI $\geq 30 \mathrm{~kg} / \mathrm{m}^{2}$ ) for all individuals aged 19 years or more was 35 and $15 \%$, respectively. Among adolescents (10-19 years old), $23 \%$ were overweight and $6 \%$ obese, according to the WHO cut-offs for BMI-for-age $(z$-scores $>+1$ SD and $>+2$ SD, respectively).

The mean total energy intake was $8024 \mathrm{~kJ}$ (1919kcal) and increased with income $(P<0 \cdot 0001)$. The contribution of macronutrients to energy intake was very similar across all age groups, varying from 15.4 to $17 \cdot 3 \%$ for proteins, 26.9 to $27 \cdot 8 \%$ for lipids and 55.6 to $57 \cdot 0 \%$ for carbohydrates. The contribution of carbohydrates to energy intake reduced with income $(57.5 \%$ in the first quartile, $56.1 \%$ in the second quartile, $55.5 \%$ in the third quartile and $54.6 \%$ in the fourth quartile). Conversely, the contribution of lipids to energy intake increased according to income $(25.9 \%$ in the first quartile, $27 \cdot 2 \%$ in the second quartile, $27 \cdot 9 \%$ in the third quartile and $28.4 \%$ in the fourth quartile). There was no significant variation in the contribution of proteins to energy intake according to income $(16.5 \%$ in the first quartile, $16.6 \%$ in the second quartile, $16.4 \%$ in the third quartile and $16.9 \%$ in the fourth quartile).
Of the study sample, $43 \%$ consumed at least one food away from home. The mean energy intake from foods consumed away from home was $1408 \mathrm{~kJ}$ (337 kcal), averaging $18 \%$ of total energy intake.

Energy consumed away from home increased with income for both sexes in all age categories, except among elderly women (Table 1). Among men, adults presented the highest percentage of energy consumed from away-from-home foods in all income levels. Among women, the contribution of away-from-home food consumption to energy intake was greater for adolescents in the first two income quartiles and very similar for adolescents and adults in the third income quartile. Only at the highest income level did adult women present a higher percentage of energy from foods consumed away from home compared with adolescents and the elderly.

Alcoholic beverages and baked and deep-fried snacks were more often consumed away from home than at home (more than $50 \%$ of the energy consumed from these groups came from away-from-home sources). Away-from-home energy sources were also high for pizza, soft drinks, sandwiches, and sweets and desserts. The lowest percentages of awayfrom-home energy intake (less than 10\%) were observed for breads, soups, milk, oils, spreads, sauces and condiments, salty meat/fish, and eggs/egg dishes (Table 2).

Of the energy consumed away from home, $50 \%$ came from rice/rice dishes, meat/meat dishes, beans/legumes, sweets and desserts, fruit juices, and baked and deep-fried snacks. The food groups that provided the lowest contributions to away-from-home energy intake were breakfast cereals, nuts, vegetables and salty meat/fish (Table 3 ).

Individuals who reported consuming foods away from home presented, on average, higher energy intake than individuals who did not eat away from home $(8670 v .7541 \mathrm{~kJ}$ (2072 v. $1802 \mathrm{kcal}) ; P<0 \cdot 0001)$. Even after controlling for age and income, away-from-home eating was positively associated with increased total energy intake for both men and women. The interaction between income and awayfrom-home eating was tested and a statistical significance was found among men $(P<0 \cdot 0001)$, but not among women $(P=0.96)$. Stratifying the analyses by income levels, we found that the relationship between total energy intake and eating away from home remained positively significant among the first three income quartiles in men. Total energy intake was not related to foods consumed away from home only among men in the highest income level (Table 4). Although income did not change the relationship between

Table 1. Contribution (\%) of away-from-home eating to the total energy intake by sex, age groups and income level of individuals living in urban areas in the 2008-9 Brazilian Nationwide Dietary Survey

\begin{tabular}{|c|c|c|c|c|c|c|}
\hline \multirow[b]{2}{*}{ Income levels (US\$) } & \multicolumn{3}{|c|}{ Men $(n 11519)$} & \multicolumn{3}{|c|}{ Women (n 14234) } \\
\hline & $\begin{array}{l}\text { Adolescent } \\
10-19 \text { years }\end{array}$ & $\begin{array}{c}\text { Adult } \\
20-59 \text { years }\end{array}$ & $\begin{array}{l}\text { Elderly } \\
60+\text { years }\end{array}$ & $\begin{array}{l}\text { Adolescent } \\
10-19 \text { years }\end{array}$ & $\begin{array}{c}\text { Adult } \\
20-59 \text { years }\end{array}$ & $\begin{array}{c}\text { Elderly } \\
60+\text { years }\end{array}$ \\
\hline First quartile $(\leq 127)$ & $11 \cdot 3$ & $17 \cdot 1$ & 5.9 & $14 \cdot 1$ & $11 \cdot 3$ & 3.5 \\
\hline Second quartile (127-236) & $14 \cdot 0$ & $18 \cdot 7$ & 4.0 & $16 \cdot 2$ & $15 \cdot 1$ & 1.8 \\
\hline Third quartile (236-499) & $16 \cdot 2$ & $22 \cdot 3$ & $9 \cdot 0$ & $19 \cdot 4$ & $19 \cdot 8$ & $4 \cdot 2$ \\
\hline Fourth quartile $(\geq 499)$ & $22 \cdot 8$ & $28 \cdot 8$ & $13 \cdot 1$ & $19 \cdot 1$ & $22 \cdot 0$ & 9.6 \\
\hline$P$ for trend & $<0.0001$ & $<0.0001$ & $<0.0001$ & 0.02 & $<0.0001$ & 0.28 \\
\hline
\end{tabular}


Table 2. Description of food groups, total energy intake from each food group $(\mathrm{kJ} / \mathrm{d})$, percentage and standard error of energy obtained from the awayfrom-home consumption of the respective food group among individuals living in urban areas in the 2008-9 Brazilian Nationwide Dietary Survey

\begin{tabular}{|c|c|c|c|c|c|}
\hline \multirow[b]{2}{*}{ Food groups } & \multirow[b]{2}{*}{ Food group description } & \multicolumn{2}{|c|}{ Energy intake } & \multicolumn{2}{|c|}{ Away from home } \\
\hline & & $\mathrm{kJ} / \mathrm{d}$ & $\mathrm{kcal} / \mathrm{d}$ & $(\%)$ & SE \\
\hline Rice/rice dishes & Rice and rice mixed dishes & 943.5 & $225 \cdot 5$ & $14 \cdot 0$ & 0.4 \\
\hline Maize/maize dishes & Maize, maize meals and maize mixed dishes & 86.4 & 20.6 & 10.5 & $1 \cdot 1$ \\
\hline Beans/legumes & Beans, bean mixed dishes, soya meat, lentils & $815 \cdot 9$ & $195 \cdot 0$ & $14 \cdot 1$ & 0.5 \\
\hline Green leafy vegetables & Lettuce, broccoli, spinach & 23.2 & 5.5 & $19 \cdot 9$ & 1.1 \\
\hline Other vegetables & Tomato, pumpkin, carrots, squash & $19 \cdot 2$ & 4.6 & $15 \cdot 7$ & 1.6 \\
\hline Potatoes & All potato items other than potato chips & $131 \cdot 4$ & 31.4 & $25 \cdot 3$ & $2 \cdot 0$ \\
\hline Other tubers & Manioc, yam and tuber products & $150 \cdot 4$ & $36 \cdot 0$ & 14.8 & 1.0 \\
\hline Fruit & All fruit and fruit salads & $226 \cdot 8$ & $54 \cdot 2$ & $16 \cdot 4$ & 0.8 \\
\hline Nuts & Nuts, seeds, peanut butter & $6 \cdot 1$ & 1.5 & 21.6 & 4.9 \\
\hline Breakfast cereals & Ready-to-eat and cooked cereals & 11.4 & $2 \cdot 7$ & $10 \cdot 6$ & 3.7 \\
\hline Pasta & Spaghetti, lasagne and other types of pasta & $248 \cdot 0$ & $59 \cdot 3$ & $17 \cdot 1$ & $1 \cdot 2$ \\
\hline Soups & Vegetable, meat and pasta soups & $117 \cdot 3$ & $28 \cdot 0$ & 8.2 & 1.0 \\
\hline Breads & White and whole-wheat breads and bread toasts & 724.5 & 173.1 & $9 \cdot 3$ & 0.4 \\
\hline Cakes and cookies & Cakes, sweet and filling cookies & 351.9 & $84 \cdot 1$ & $21 \cdot 1$ & $1 \cdot 2$ \\
\hline Savoury snacks & Crackers and potato/corn chips & $137 \cdot 8$ & $32 \cdot 9$ & $22 \cdot 3$ & $2 \cdot 1$ \\
\hline Meat/meat dishes & Meat and meat mixed dishes & $740 \cdot 8$ & $177 \cdot 0$ & $18 \cdot 0$ & 0.8 \\
\hline Pork/pork dishes & Pork and pork mixed dishes & 105.4 & $25 \cdot 2$ & $20 \cdot 2$ & $3 \cdot 1$ \\
\hline Poultry/poultry dishes & Poultry and poultry mixed dishes & 378.6 & 90.5 & $17 \cdot 9$ & 0.9 \\
\hline Fish/fish dishes & Fish, shellfish and fish mixed dishes & $108 \cdot 7$ & $26 \cdot 0$ & $13 \cdot 1$ & 1.4 \\
\hline Salty meat/fish & Meat and fish preserved with salt & 44.4 & $10 \cdot 6$ & $8 \cdot 1$ & 1.4 \\
\hline Processed meat & Ham, sausage, franks and other luncheon meat & $123 \cdot 8$ & $29 \cdot 6$ & 12.5 & 1.9 \\
\hline Eggs & Eggs and egg mixed dishes & 97.8 & 23.4 & 7.5 & 0.7 \\
\hline Milk & Fluid milk, yogurt and chocolate milk & $297 \cdot 7$ & $71 \cdot 1$ & 8.7 & 0.6 \\
\hline Cheeses & Mozzarella, cottage, cheddar and other cheeses & 94.0 & 22.5 & $10 \cdot 0$ & $1 \cdot 1$ \\
\hline Sweets and desserts & Sugar, sugar substitute, honey, milk and fruit desserts, candies & $312 \cdot 6$ & 74.7 & 29.6 & 1.7 \\
\hline Oils, spreads, sauces and condiments & Vegetable oils, olive oil, butter, margarine, mayonnaise & 208.6 & 49.9 & $7 \cdot 8$ & 0.5 \\
\hline Alcoholic beverages & Beer, wine and other distilled beverages & 77.6 & $18 \cdot 6$ & $58 \cdot 6$ & 3.5 \\
\hline Fruit juices & $100 \%$ and flavoured fruit juices & $451 \cdot 3$ & $107 \cdot 9$ & 20.4 & 0.7 \\
\hline Coffee and tea & Coffee, cappuccino, tea & 457.5 & $109 \cdot 3$ & 10.5 & 0.4 \\
\hline Soft drinks & Regular and diet/light soft drinks & $165 \cdot 8$ & 39.6 & 40.4 & 1.4 \\
\hline Pizza & Pizzas and rolls & $64 \cdot 6$ & $15 \cdot 4$ & $42 \cdot 0$ & $5 \cdot 8$ \\
\hline Baked and deep-fried snacks & Salty pastries, chicken/meat/cheese patties, deep-fried snacks & 135.9 & 32.5 & 53.8 & $2 \cdot 2$ \\
\hline Sandwiches & Hamburgers, cheeseburgers, hotdogs and other sandwiches & 164.8 & 39.4 & 39.7 & $2 \cdot 3$ \\
\hline
\end{tabular}

away-from-home eating and energy intake among women, we also evaluated the relationship between eating away from home and total energy intake by income levels and found that among women, only in the third quartile was there no significant association (Table 4).

\section{Discussion}

The present study is based on the first Brazilian Nationwide Dietary Survey, and describes all foods prepared and consumed away from home and points out the major energy sources from away-from-home food consumption in urban areas. Of the study sample, $43 \%$ reported consuming at least one food away from home. The fraction of mean energy intake from away-from-home eating was $18 \%$, varying between $2 \%$ among elderly women in the second quartile of income and 29\% among adult men in the highest income level. In the multivariate analysis, even after controlling for age and income, eating away from home was positively associated with increased total energy intake among both men and women.

Direct comparisons with other studies are limited due to different methods applied as well as differences in the definition of away-from-home food, and the age and socio-economic profiles of the samples. In other studies, the contribution of energy from away-from-home foods to total energy intake ranged from $11 \%$ among adults between 35 and 74 years old investigated in ten European countries using a more restrictive definition of substantial away-fromhome consumers (individuals consuming $\geq 25 \%$ of their daily energy intake from away-from-home food sources reported in one $24 \mathrm{~h}$ recall) to $50 \%$ among adolescents between 13 and 19 years old as evaluated by the average of two $24 \mathrm{~h}$ dietary recalls collected only on their school days in Cotonou, Benin ${ }^{(6,9,15,16,25,26)}$. Previous studies ${ }^{(3,4,9,11,15,27-31)}$ also reported that individuals who consumed foods away from home presented higher energy intake than nonconsumers.

Many mechanisms have been suggested to explain the pathway between the consumption of food away from home and excessive energy intake including high energy density, high fat content, low fibre content, large portion sizes, high palatability and high variability ${ }^{(32-39)}$. Although the results of the studies that investigated the relationship of away-fromhome eating and weight gain are controversial ${ }^{(2,15,23,40-42)}$, it can be stated that away-from-home food consumers present higher energy intake than non-consumers.

In the present study, the percentage of energy from awayfrom-home food was generally higher in adults and men, as well as among high-income individuals. The role of income 
Table 3. Contribution (\%) of food groups to away-from-home energy intake of individuals living in urban areas in the 2008-9 Brazilian Nationwide Dietary Survey

\begin{tabular}{|c|c|c|c|}
\hline Food group categories & Contribution to away-from-home energy intake & SE & Cumulative contribution \\
\hline Rice/rice dishes & $9 \cdot 4$ & $0 \cdot 2$ & $9 \cdot 4$ \\
\hline Meat/meat dishes & $9 \cdot 4$ & 0.4 & $18 \cdot 8$ \\
\hline Beans/legumes & $8 \cdot 2$ & 0.3 & $27 \cdot 0$ \\
\hline Sweets and desserts & $6 \cdot 6$ & 0.5 & $33 \cdot 6$ \\
\hline Fruit juices & $6 \cdot 5$ & 0.2 & $40 \cdot 1$ \\
\hline Cakes and cookies & $5 \cdot 3$ & 0.3 & $45 \cdot 4$ \\
\hline Baked and deep-fried snacks & $5 \cdot 2$ & 0.3 & $50 \cdot 6$ \\
\hline Poultry/poultry dishes & $4 \cdot 8$ & 0.2 & $55 \cdot 4$ \\
\hline Breads & $4 \cdot 8$ & 0.2 & $60 \cdot 2$ \\
\hline Soft drinks & $4 \cdot 8$ & 0.2 & $65 \cdot 0$ \\
\hline Sandwiches & 4.6 & 0.3 & $69 \cdot 6$ \\
\hline Coffee and tea & 3.4 & 0.1 & $73 \cdot 0$ \\
\hline Alcoholic beverages & $3 \cdot 2$ & 0.3 & $76 \cdot 2$ \\
\hline Pasta & $3 \cdot 0$ & 0.2 & $79 \cdot 2$ \\
\hline Fruit & $2 \cdot 6$ & 0.1 & $81 \cdot 8$ \\
\hline Potatoes & 2.4 & 0.2 & $84 \cdot 2$ \\
\hline Savoury snacks & $2 \cdot 2$ & 0.2 & $86 \cdot 4$ \\
\hline Pizza & 1.9 & 0.3 & $88 \cdot 3$ \\
\hline Milk & $1 \cdot 8$ & 0.1 & $90 \cdot 1$ \\
\hline Other tubers & 1.6 & 0.1 & 91.7 \\
\hline Pork/pork dishes & 1.5 & 0.3 & $93 \cdot 2$ \\
\hline Oils, spreads, sauces and condiments & $1 \cdot 2$ & 0.1 & 94.4 \\
\hline Processed meat & $1 \cdot 1$ & $0 \cdot 2$ & 95.5 \\
\hline Fish/fish dishes & $1 \cdot 0$ & 0.1 & $96 \cdot 5$ \\
\hline Cheeses & 0.7 & $0 \cdot 1$ & $97 \cdot 2$ \\
\hline Soups & 0.7 & 0.1 & $97 \cdot 9$ \\
\hline Maize/maize dishes & 0.6 & $0 \cdot 1$ & 98.5 \\
\hline Eggs & 0.5 & 0.1 & $99 \cdot 0$ \\
\hline Salty meat/fish & 0.3 & * & $99 \cdot 3$ \\
\hline Green leafy vegetables & 0.3 & * & $99 \cdot 0$ \\
\hline Other vegetables & 0.2 & * & $99 \cdot 8$ \\
\hline Nuts & 0.1 & * & 99.9 \\
\hline Breakfast cereals & 0.1 & * & 100 \\
\hline
\end{tabular}

as an important factor with away-from-home eating has previously been reported ${ }^{(17,19,43)}$. In addition, other studies have reported on the higher intake of away-from-home foods among men and young adults ${ }^{(19,44)}$.

The present data indicate that socio-economic status modified the association between away-from-home eating and total energy intake among men, suggesting that those in the lowest income levels select more energy-dense foods when eating away from home than men in the highest income level. Although the percentage of away-from-home energy intake within food groups increased with income for almost all food groups, important differences according to the type of group consumed were observed. The contribution of rice/ rice dishes, beans/legumes and vegetables to away-fromhome energy intake among men in the highest income level is almost three times higher than among men in the lowest income level. However, this same trend is not observed when we evaluated the contribution of soft drinks, pizza, baked and deep-fried snacks, and sandwiches consumed away from home. The energy from pizza consumed away from home among men in the lowest income level was higher than the energy from away-from-home pizza among

Table 4. Weighted regression coefficients $(\beta)$ of linear model with log of total energy intake as the dependent variable and eating away from home (yes/no) as the independent variable, according to sex and income levels of individuals living in urban areas in the $2008-9$ Brazilian Nationwide Dietary Survey*

( $\beta$ Coefficients and $95 \%$ confidence intervals)

\begin{tabular}{|c|c|c|c|c|c|c|}
\hline \multirow[b]{2}{*}{ Income levels (US\$) } & \multicolumn{3}{|c|}{ Men } & \multicolumn{3}{|c|}{ Women } \\
\hline & $\beta$ & $95 \% \mathrm{Cl}$ & $P \dagger$ & $\beta$ & $95 \% \mathrm{Cl}$ & $P \dagger$ \\
\hline First quartile $(\leq 127)$ & 0.15 & $0.08,0.21$ & $<0.0001$ & $0 \cdot 10$ & $0.06,0.15$ & $<0.0001$ \\
\hline Second quartile $(127-236)$ & 0.11 & $0.06,0.16$ & $<0.0001$ & 0.08 & $0.03,0.12$ & 0.0008 \\
\hline Third quartile $(236-499)$ & 0.09 & $0.04,0.13$ & 0.0002 & 0.04 & $-0.002,0.09$ & 0.06 \\
\hline Fourth quartile $(\geq 499)$ & -0.003 & $-0.06,0.06$ & 0.92 & 0.07 & $0.02,0.11$ & 0.006 \\
\hline
\end{tabular}


men in the highest income level ( $73 v .45 \%$, respectively). The percentage of energy from away-from-home soft drinks on the total energy consumed from soft drinks was $41 \%$ among men in the lowest income level and 52\% among men in the highest income level. For baked and deep-fried snacks, the percentages were 54 and $57 \%$, respectively, while for sandwiches the percentage was the same (data not shown).

These findings are particularly important from a public health perspective, considering that away-from-home food consumption might be related to total energy intake differently according to the income levels, which must be taken into account in the design of food and nutrition policies, for example facilitating the access to healthy food items to low- and middle-income people.

Alcoholic beverages and baked and deep-fried snacks were consumed in greater proportions away from home than at home. Pizzas, soft drinks, sandwiches, and sweets and desserts were also highly consumed away from home. These results are consistent with other studies ${ }^{(9,15,17,45,46)}$ and raise important concerns regarding the role of foods consumed away from home on the quality of the diet in Brazilian urban areas. The consumption of baked and deep-fried snacks and pizza can add important amounts of saturated fat, trans-fat and $\mathrm{Na}$ to the diet, which are known to increase the risk of weight gain, insulin resistance and $\operatorname{CVD}^{(10,28,40)}$. Several studies have found that away-from-home eating is associated with higher total fat and $\mathrm{Na}$ consumption than the eating of at-home foods ${ }^{(9,10,12,15,47)}$. Additionally, the high consumption of soft drinks away from home is another important aspect that can have a negative impact on health, since it is suggested that the intake of energy in liquid form confers less satiety, decreasing the mechanisms of energy intake compensation in comparison with solid foods, thus contributing to high energy intake and weight gain ${ }^{(48-50)}$.

In the present study, the consumption of sandwiches should be evaluated with caution due to a possible underestimation that may have happened as respondents could detail the ingredients of their sandwiches or simply report a whole sandwich, for example a grilled cheese sandwich. In the present analysis, in the sandwich group, we only included sandwiches that were reported as single items.

We calculated the ratio of away-from-home energy intake by food group to total away-from-home energy intake, and found that rice/rice dishes, meat/meat dishes and beans/ legumes were the groups that most contributed to the total energy consumed away from home. The combination of rice, beans and meat represents a traditional meal in Brazil, mostly consumed at lunch and dinner, indicating that awayfrom-home food may be mostly consumed during these meal occasions and most probably related to time constraints encountered during working hours ${ }^{(51)}$.

The inclusion of alcoholic beverages in analyses of awayfrom-home food consumption has been questioned since there are individuals who consumed only alcoholic beverages away from home and because alcoholic beverages can contain non-ethanol energy sources ${ }^{(14)}$. Nevertheless, excluding alcoholic beverages from the analysis did not change the contribution of foods consumed away from home to the total energy intake (from 18 to $17 \%$, respectively) nor the rank of food groups in the contribution to away-from-home energy intake.

A negative aspect of foods consumed away from home in Brazilian urban areas is the high level of sweets and desserts, leading to both a high percentage of energy consumed away from home and important contributions to away-from-home energy intake. Diets with high amounts of sugars and sweet foods usually have high contents of energy and low amounts of vitamins and minerals ${ }^{(9)}$.

The limitations of the present study are the effects of underreporting of specific subgroups, such as women and obese individuals, and the inherent limitations of food records, in that they are subject to modification by the intake of individuals on reporting days ${ }^{(52,53)}$. Another limitation is the definition used to identify away-from-home foods in the survey, which does not include foods that were prepared away from home and consumed at home, such as takeaway and home delivery foods, which are known to be rich in fat and energy ${ }^{(47)}$. Another important issue in terms of public health nutrition and policy perspective is the evaluation of the places where people eat out, but this information was not collected in the dietary survey.

We found evidence that away-from-home food consumption is associated with increased energy intake, except for men in the highest income level. Additionally, socio-economic status was positively associated with a greater contribution of foods consumed away from home to the total energy intake. These observations suggest that the influence of awayfrom-home food consumption on diet quality varies according to socio-economic status. Overall, the present findings highlight the high intake of foods with a high content of energy in away-from-home settings, such as alcoholic beverages, baked and deep-fried snacks, pizza, soft drinks, and sweets and desserts. Consequently, away-from-home food consumption may be linked to adverse health outcomes, in particular weight gain. More in-depth studies on the nutritional contributions of foods consumed away from home to the overall Brazilian diet and the socio-economic differences related to this issue are necessary to properly design and target strategies for moderating energy intake and enhancing diet quality in this country.

\section{Acknowledgements}

The survey was funded by the Ministry of Health of Brazil. I. N. B. received a fellowship from the Brazilian Federal Agency for the Improvement of Higher Education (Coordenação de Aperfeiçoamento de Pessoal de Nível Superior; CAPES) - process no. 6748-10-4. R. S. and R. A. P. contributed to the design of the study. I. N. B. and A. d. M. S. contributed to the analysis and interpretation of the data, and the drafting of the manuscript. All authors read and approved the final manuscript. None of the authors has conflicts of interest.

\section{References}

1. US Department of Agriculture (2010) Report of the Dietary Guidelines Advisory Committee on the Dietary Guidelines 
for Americans, 2010. Washington, DC: US Department of Agriculture.

2. Clemens LH, Slawson DL \& Klesges RC (1999) The effect of eating out on quality of diet in premenopausal women. $J \mathrm{Am}$ Diet Assoc 99, 442-444.

3. French SA, Harnack L \& Jeffery RW (2000) Fast food restaurant use among women in the Pound of Prevention study: dietary, behavioral and demographic correlates. Int J Obes Relat Metab Disord 24, 1353-1359.

4. Bowman SA \& Vinyard BT (2004) Fast food consumption of U.S. adults: impact on energy and nutrient intakes and overweight status. J Am Coll Nutr 23, 163-168.

5. Lachat C, Nago E, Verstraeten R, et al. (2012) Eating out of home and its association with dietary intake: a systematic review of the evidence. Obes Rev 13, 329-346.

6. Paeratakul S, Ferdinand DP, Champagne CM, et al. (2003) Fast-food consumption among US adults and children: dietary and nutrient intake profile. J Am Diet Assoc 103, $1332-1338$.

7. Bowman SA, Gortmaker SL, Ebbeling CB, et al. (2004) Effects of fast-food consumption on energy intake and diet quality among children in a national household survey. Pediatrics 113, 112-118.

8. Bes-Rastrollo M, Basterra-Gortari FJ, Sanchez-Villegas A, et al. (2010) A prospective study of eating away-from-home meals and weight gain in a Mediterranean population: the SUN (Seguimiento Universidad de Navarra) cohort. Public Health Nutr 13, 1356-1363.

9. Kearney JM, Hulshof KF \& Gibney MJ (2001) Eating patternstemporal distribution, converging and diverging foods, meals eaten inside and outside of the home-implications for developing FBDG. Public Health Nutr 4, 693-698.

10. Burns C, Jackson M, Gibbons C, et al. (2002) Foods prepared outside the home: association with selected nutrients and body mass index in adult Australians. Public Health Nutr 5, 441-448.

11. Guthrie JF, Lin BH \& Frazao E (2002) Role of food prepared away from home in the American diet, 1977-78 versus 1994-96: changes and consequences. J Nutr Educ Behav 34, 140-150.

12. Kant AK \& Graubard BI (2004) Eating out in America, 1987-2000: trends and nutritional correlates. Prev Med 38, 243-249.

13. O'Dwyer NA, Gibney MJ, Burke SJ, et al. (2005) The influence of eating location on nutrient intakes in Irish adults: implications for developing food-based dietary guidelines. Public Health Nutr 8, 258-265.

14. Orfanos P, Naska A, Trichopoulou A, et al. (2009) Eating out of home: energy, macro- and micronutrient intakes in 10 European countries. The European Prospective Investigation into Cancer and Nutrition. Eur J Clin Nutr $\mathbf{6 3}$, Suppl. 4, S239-S262.

15. van't Riet H, den Hartog AP \& van Staveren WA (2002) Non-home prepared foods: contribution to energy and nutrient intake of consumers living in two low-income areas in Nairobi. Public Health Nutr 5, 515-522.

16. Nago ES, Lachat CK, Huybregts L, et al. (2010) Food, energy and macronutrient contribution of out-of-home foods in school-going adolescents in Cotonou, Benin. $\mathrm{Br} J \mathrm{Nutr}$ 103, 281-288.

17. Lachat C, Khanh le NB, Khan NC, et al. (2009) Eating out of home in Vietnamese adolescents: socioeconomic factors and dietary associations. Am J Clin Nutr 90, 1648-1655.

18. Levy-Costa RB, Sichieri R, Pontes NS, et al. (2005) Household food availability in Brazil: distribution and trends (1974-2003). Rev Saude Publica 39, 530-540.
19. Bezerra IN \& Sichieri R (2010) Characteristics and spending on out-of-home eating in Brazil. Rev Saude Publica $\mathbf{4 4}$, 221-229.

20. Moshfegh A, Rhodes D, Baer D, et al. (2008) The US Department of Agriculture Automated Multiple-Pass Method reduces bias in the collection of energy intakes. Am J Clin Nutr 88, 324-332.

21. Instituto Brasileiro de Geografia e Estatística (IBGE) (2011) Pesquisa de Orçamentos Familiares 2008-2009: Tabelas de Composição Nutricional de Alimentos Consumidos no Brasil (Consumer Expenditure Survey: Tables of Nutritional Composition of Food Consumed in Brazil). Rio de Janeiro: Instituto Brasileiro de Geografia e Estatística (IBGE), Ministério do Planejamento, Orçamento e Gestão.

22. Instituto Brasileiro de Geografia e Estatística (IBGE) (2011) Pesquisa de Orçamentos Familiares 2008-2009: Tabela de Medidas Referidas para os Alimentos Consumidos no Brasil (Consumer Expenditure Survey: Table of Reference measures for Food Consumed in Brazil). Rio de Janeiro: Instituto Brasileiro de Geografia e Estatística (IBGE), Ministério do Planejamento, Orçamento e Gestão.

23. Bezerra IN \& Sichieri R (2009) Eating out of home and obesity: a Brazilian nationwide survey. Public Health Nutr 12, 2037-2043.

24. Subar AF, Kipnis V, Troiano RP, et al. (2003) Using intake biomarkers to evaluate the extent of dietary misreporting in a large sample of adults: the OPEN study. Am J Epidemiol 158, $1-13$.

25. Burke SJ, McCarthy SN, O'Neill JL, et al. (2007) An examination of the influence of eating location on the diets of Irish children. Public Health Nutr 10, 599-607.

26. Orfanos P, Naska A, Trichopoulos D, et al. (2007) Eating out of home and its correlates in 10 European countries. The European Prospective Investigation into Cancer and Nutrition (EPIC) study. Public Health Nutr 10, 1515-1525.

27. McCrory MA, Fuss PJ, Hays NP, et al. (1999) Overeating in America: association between restaurant food consumption and body fatness in healthy adult men and women ages 19 to 80 . Obes Res 7, 564-571.

28. Satia JA, Galanko JA \& Siega-Riz AM (2004) Eating at fastfood restaurants is associated with dietary intake, demographic, psychosocial and behavioural factors among African Americans in North Carolina. Public Health Nutr 7, 1089-1096.

29. Schmidt M, Affenito SG, Striegel-Moore R, et al. (2005) Fast-food intake and diet quality in black and white girls: the National Heart, Lung, and Blood Institute Growth and Health Study. Arch Pediatr Adolesc Med 159, 626-631.

30. Taveras EM, Berkey CS, Rifas-Shiman SL, et al. (2005) Association of consumption of fried food away from home with body mass index and diet quality in older children and adolescents. Pediatrics 116, 518-524.

31. Mancino L, Todd J \& Lin B-H (2009) Separating what we eat from where: measuring the effect of food away from home on diet quality. Food Policy 34, 557-562.

32. McCrory MA, Fuss PJ, Saltzman E, et al. (2000) Dietary determinants of energy intake and weight regulation in healthy adults. J Nutr 130, 276S-279S.

33. Young LR \& Nestle M (2002) The contribution of expanding portion sizes to the US obesity epidemic. Am J Public Health 92, 246-249.

34. Nielsen SJ \& Popkin BM (2003) Patterns and trends in food portion sizes, 1977-1998. JAMA 289, 450-453.

35. Prentice AM \& Jebb SA (2003) Fast foods, energy density and obesity: a possible mechanistic link. Obes Rev 4, 187-194. 
36. Sorensen LB, Moller P, Flint A, et al. (2003) Effect of sensory perception of foods on appetite and food intake: a review of studies on humans. Int $J$ Obes Relat Metab Disord 27, $1152-1166$

37. Isganaitis E \& Lustig RH (2005) Fast food, central nervous system insulin resistance, and obesity. Arterioscler Thromb Vasc Biol 25, 2451-2462.

38. Norton GN, Anderson AS \& Hetherington MM (2006) Volume and variety: relative effects on food intake. Physiol Behav 87, 714-722

39. Rolls BJ (2009) The relationship between dietary energy density and energy intake. Physiol Behav 97, 609-615.

40. Binkley JK, Eales J \& Jekanowski M (2000) The relation between dietary change and rising US obesity. Int $J$ Obes Relat Metab Disord 24, 1032-1039.

41. Pereira MA, Kartashov AI, Ebbeling CB, et al. (2005) Fast-food habits, weight gain, and insulin resistance (the CARDIA study): 15-year prospective analysis. Lancet 365, 36-42.

42. Naska A, Orfanos P, Trichopoulou A, et al. (2011) Eating out, weight and weight gain. A cross-sectional and prospective analysis in the context of the EPIC-PANACEA study. Int $J$ Obes (Lond) 35, 416-426.

43. Claro RM, Levy RB \& Bandoni DH (2009) [Influence of income on food expenditures away from home among Brazilian families, 2002-2003]. Cad Saude Publica 25, 2489-2496.

44. Anderson B, Rafferty AP, Lyon-Callo S, et al. (2011) Fast-food consumption and obesity among Michigan adults. Prev Chronic Dis 8, A71.
45. French SA, Story M, Neumark-Sztainer D, et al. (2001) Fast food restaurant use among adolescents: associations with nutrient intake, food choices and behavioral and psychosocial variables. Int J Obes Relat Metab Disord 25, 1823-1833.

46. Vandevijvere S, Lachat C, Kolsteren P, et al. (2009) Eating out of home in Belgium: current situation and policy implications. Br J Nutr 102, 921-928.

47. Lin BH, Frazão E \& Guthrie J (1999) Away-from-home foods increasingly important to quality of American diet. In Agriculture Information Bulletin no. 749. Washington, DC: US Department of Agriculture, Economic Research Service.

48. Bellisle F \& Drewnowski A (2007) Intense sweeteners, energy intake and the control of body weight. Eur J Clin Nutr 61, 691-700.

49. Drewnowski A \& Bellisle F (2007) Liquid calories, sugar, and body weight. Am J Clin Nutr 85, 651-661.

50. Wolf A, Bray GA \& Popkin BM (2008) A short history of beverages and how our body treats them. Obes Rev 9, $151-164$

51. Jabs J \& Devine CM (2006) Time scarcity and food choices: an overview. Appetite 47, 196-204.

52. Rebro SM, Patterson RE, Kristal AR, et al. (1998) The effect of keeping food records on eating patterns. J Am Diet Assoc 98, 1163-1165.

53. Scagliusi FB, Ferriolli E, Pfrimer K, et al. (2008) Underreporting of energy intake in Brazilian women varies according to dietary assessment: a cross-sectional study using doubly labeled water. J Am Diet Assoc 108, 2031-2040. 